Original Research

\title{
Measuring the proportion of time spent on work activities of clinical pharmacists using work sampling technique at a public hospital in Malaysia
}

\author{
Kian K. KONG (iD), Siew C. ONG (D), Guat S. OOI (iD), Mohamed A. HASSALI (D). \\ Received (first version): 23-Jun-2021 Accepted: 23-Aug-2021 Published online: 6-Sep-2021
}

\begin{abstract}
Background: The clinical pharmacy service to the ward was established in 2005 in Malaysia, as the number of pharmacists working in the public service sector began to grow. Yet, there has been little local research done on reporting the range of work activities of clinical pharmacists and the amount of time that they spent on their work activities.

Objective: This study aimed to identify the range of work activities of clinical pharmacists by observation and to estimate the proportion of time spent on different work activities by using the work sampling technique.

Methods: The time spent by clinical pharmacists on various activities was measured using the work sampling technique over 30 working days. The work activities of clinical pharmacists were pre-identified and customized into an activity checklist. Two observers were placed at the study site and took turns recording the activities performed by the clinical pharmacists by following a randomly generated observation schedule.

Results: 1,455 observations were made on five clinical pharmacists with a total of 3493 events recorded. Overall, clinical pharmacists spent $78.8 \%(n=2751)$ of their time providing clinical services whereas $12.3 \%(n=433)$ of their time was spent on non-clinical activities. They were found to be idle from work for $8.9 \%$ of the time. There was no difference in bed occupancy rate in the study site regardless of the presence of the observer $(\mathrm{p}=0.384)$. Clinical pharmacists were found to report a higher average daily cumulative work unit of 9.8 $(S D=4.3)$ when under observation compared to an average daily cumulative work unit of $6.5(S D=4.6)$ when no observer was present $(\mathrm{p}=0.005)$.

Conclusions: The results revealed that clinical pharmacists spent a significant amount of time on non-clinical work. Their responsibilities with non-clinical work should be properly taken care of so they can allocate more time to providing patient care.
\end{abstract}

\section{Keywords}

Pharmacists; Professional Practice; Workload; Clinical Competence; Pharmacy Service, Hospital; Quality of Health Care; Observation; Management Audit; Behavior Observation Techniques; Malaysia

\section{INTRODUCTION}

Pharmacy services started in Malaysia in 1951 whereby the core services were confined fundamentally to procurement, storage, and distribution of drugs. ${ }^{1}$ Since then, the focus of pharmaceutical services has gradually shifted towards enhancing patient safety, drug therapy optimization, and medication error prevention. As a remedial measure to control the serious shortage of pharmacists in the public services in 2005, the Pharmacy Board Malaysia mandated a four-year compulsory service program in the public sector for all the pharmacy graduates in Malaysia. ${ }^{1,2}$ As a result of this intervention, the number of pharmacists being retained in the public sector increased significantly and this had made the establishment and expansion of the pharmacy service within the Ministry of Health possible.

\footnotetext{
Kian Keong KONG. Clinical Research Centre, Duchess of Kent Hospital, Ministry of Health Malaysia. Malaysia.

keongmy85@hotmail.com

Siew Chin ONG. Discipline of Social and Administrative Pharmacy, School of Pharmaceutical Sciences, University of Science Malaysia. Penang (Malaysia). oschin99@yahoo.com

Guat See OOI. Discipline of Clinical Pharmacy, School of

Pharmaceutical Sciences, University of Science Malaysia. Penang

(Malaysia).guatsee.ooi@usm.my

Mohamed Azmi Ahmad HASSALI*. Discipline of Social and

Administrative Pharmacy, School of Pharmaceutical Sciences,

University of Science Malaysia. Penang (Malaysia).

azmihassali@gmail.com

*Deceased
}

Subsequently, the pharmacy service in the public sector has then been expanded to provide various services, such as inpatient pharmacy, clinical pharmacy service, medication therapy adherence clinic, clinical pharmacokinetic services, and many other services. ${ }^{1}$ In contrast, the pharmacy service in the private sector has only offered a portion of the available services in the public sector owing to limited funding. In 2016, a new contract-based employment system was implemented in response to the demand for resident positions exceeding the number of available training positions among pharmacy graduates. This change has led to a high staff turnover rate and an increased number of pharmacists leaving the public services, particularly those who were employed on a contract basis. $^{3,4}$

With a sharp decrease in the number of long-term pharmacists working in the public sector, those who remained were required to share the work burden of those who had left on top of their usual job scope. As a result, the daily tasks of hospital pharmacists particularly those who were involved primarily in clinical works were reassigned to take up non-clinical tasks that were outside of their clinical specialties, such as managerial works and logistics arrangements. However, there has been limited up-to-date local research done on the reporting of the hospital pharmacist's work activities, making the task reassignment activities extremely difficult. 
In the Malaysian system of pharmacy practice to date, the role of pharmacists is very confined to the area of service that they have been assigned to. For instance, the job scope of pharmacists is very limited to prescription screening, preparing, and dispensing if they are stationed at the outpatient dispensary. Commonly, these pharmacists are not involved in activities that are out of the area of service that they are being stationed at. In contrast, those who are involved in clinical pharmacy play bigger roles in patient care, from the point of patient admission until discharge, and cover outpatient care. Additionally, they have more opportunities to work with the different disciplinary teams in the care management of patients in the ward setting. ${ }^{1}$ For this reason, clinical pharmacy has become a successful principal practice model in the pharmacy practice of Malaysia and around the world. ${ }^{5}$

Clinical pharmacists in the Malaysian public sector pharmacy visit wards on daily basis to participate in ward rounds and to monitor both the progression of patients' condition and prescriptions. ${ }^{6}$ Despite the contribution of clinical pharmacists in improving health outcomes as demonstrated in many studies, there has been limited data available on the range of their work activities that give rise to such outcomes. ${ }^{7-13}$ Moreover, the literature available on clinical pharmacy in Malaysia has been commonly referenced using studies from other countries. Thus, there is a growing interest in research that evaluates and assesses services delivering efficiency in the field of pharmacy.

The work activity measurement in the field of pharmacy was commonly reported using the work sampling technique. ${ }^{14-17}$ A work sampling is a time utilization research technique applied to estimate the percentage of time spent by a person in various defined categories of activity through many observations taken at either random or fixed intervals. When the number of random observations taken is large enough, the observations would represent the proportion of time spent by the person on

\begin{tabular}{|c|c|}
\hline Code & Category \\
\hline \multicolumn{2}{|c|}{ Clinical activity } \\
\hline 1. & $\begin{array}{l}\text { Participating in ward round } \\
\text { Participation in ward rounds with other healthcare teams; update the status of the care management plan for patients. }\end{array}$ \\
\hline 2. & $\begin{array}{l}\text { Medication history assessment \& reconciliation } \\
\text { Patient prescription and non-prescription medication history taking on admission; medication reconciliation on admission; } \\
\text { patient medication adherence assessment; }\end{array}$ \\
\hline 3. & $\begin{array}{l}\text { Case clerking and medication review } \\
\text { Clerking case; reviewing medication/ IV therapy chart; annotating chart; reviewing patient case progression in medical } \\
\text { records; interviewing patient/ family member/ caregiver on the health condition progression during hospitalization }\end{array}$ \\
\hline 4. & $\begin{array}{l}\text { Counselling } \\
\text { Giving counselling on the prescribed medication or devices e.g. metered dose inhaler for asthma; providing information } \\
\text { on the disease state, medications supplied, potential side effects, etc.; providing counselling while dispensing medication } \\
\text { during discharge. }\end{array}$ \\
\hline 5. & $\begin{array}{l}\text { Discharge planning } \\
\text { Continuity of care referral; prescription processing for discharge; medication reconciliation for discharge; filled } \\
\text { prescriptions proof checking; discharge plan documentation }\end{array}$ \\
\hline 6. & $\begin{array}{l}\text { Distribution of information } \\
\text { Searching information for evidence-based medicine; providing drug information service }\end{array}$ \\
\hline 7. & $\begin{array}{l}\text { Clinical risk management and drug surveillance } \\
\text { Therapeutic drug monitoring; parenteral nutrition preparation; reporting adverse drug reaction; reporting drug allergy; } \\
\text { reporting medication error; lodging product complaint }\end{array}$ \\
\hline 8. & $\begin{array}{l}\text { Special authorization drug request processing } \\
\text { Processing antimicrobial agent requiring special authorization; processing medication request for treatment requiring } \\
\text { special authorization }\end{array}$ \\
\hline 9. & $\begin{array}{l}\text { Conducting intervention and keeping clinical records } \\
\text { Carrying out pharmaceutical care intervention; recording keynotes in the notebook; documenting interventions in medical } \\
\text { records and electronic reporting system }\end{array}$ \\
\hline 10. & $\begin{array}{l}\text { Health communication } \\
\text { Pharmaceutical care intervention related contact with other healthcare professionals; updating clinical information of } \\
\text { patients among colleagues; providing reassurance to simple queries from colleagues }\end{array}$ \\
\hline \multicolumn{2}{|r|}{ Non-clinical activity } \\
\hline 11. & $\begin{array}{l}\text { Pharmacy administration and management } \\
\text { Quality assurance and auditing; organizational activity (such as human resource management/ updating service records, } \\
\text { attending a meeting, or preparing work for a meeting); work productivity reporting; logistics process and reporting. }\end{array}$ \\
\hline 12. & $\begin{array}{l}\text { Educational activities } \\
\text { Pharmacy education; short training session/ case presentation session among colleagues; supervising an intern at work; } \\
\text { continuing medical education/ short refresher course. }\end{array}$ \\
\hline 13. & $\begin{array}{l}\text { Research-related activities } \\
\text { Includes literature search, research protocol writing, discussion, data collection and analysis, and result write-up. }\end{array}$ \\
\hline 14. & $\begin{array}{l}\text { Non-duty activities } \\
\text { Preparing or conducting work not part of the daily duty; organizing drug chart/ assisting nursing staffs or patients }\end{array}$ \\
\hline 15. & $\begin{array}{l}\text { Non-professional activities } \\
\text { Walking; transporting things; general chat among colleagues or other healthcare professionals }\end{array}$ \\
\hline \multicolumn{2}{|r|}{ ( } \\
\hline 16. & $\begin{array}{l}\text { Idle or work break } \\
\quad \text { Taking a break; physiological need at work; using smartphone; private use }\end{array}$ \\
\hline
\end{tabular}


each of the predefine activities with good accuracy. This method is favourable in pharmacy research as it allows the measurement of work activities of non-repetitive and irregular work cycles in nature. ${ }^{12,17}$ Results of clinical pharmacist-related work activities using the work sampling technique have been reported in many other countries. Relevant examples include its use in Australia, the UK, and the USA to study how clinical pharmacists spent their working time and documented their range of work; in Japan to measure work activities of clinical pharmacists; in Thailand to measure the time utilization at work in the outpatient pharmacy setting. ${ }^{18-23}$

As the first step to determine which of the clinical pharmacy tasks should be performed by other staff or should clinical pharmacists be given more responsibility, the present study aimed to identify the range of work activities of clinical pharmacists working in the public hospital, and estimating the proportion of time that they spent on different work activities by using the work sampling technique.

\section{METHODS}

\section{Study design}

This was a cross-sectional observational study carried out by using the work sampling technique in a 400 -bed public hospital. The study site is a teaching hospital equipped with a pharmacy information system that is integrated with all the pharmacy-related services.

\section{Ethics approval}

This study was registered with the National Medical Research Register Malaysia and was approved by the Medical Research and Ethics Committee Malaysia (NMRR18-3909-44471). Written informed consent was taken from the participants before the data collection.

\section{Participants}

The complete list of the 62 hospital pharmacists working in different pharmacy units, such as out-patient pharmacy, inpatient pharmacy, clinical pharmacy, and logistic pharmacy, was obtained from the Hospital Pharmacy Department. The eligibility criteria of the target participants of the present study are the clinical pharmacists working in the ward setting on a full-time basis who conduct daily ward visits, ward round, bedside patient counselling, and patient clinical care plan management.

A total of 11 pharmacists who fulfilled the eligibility criteria were approached and invited into the study through the convenience sampling method. The routine working schedule of the pharmacists was determined before the study to reduce the likelihood of unplanned leave or other situations that could jeopardize the data collection process.

\section{Observer}

The work activities of the selected clinical pharmacists were observed and recorded by an observer. The present study also determined if the presence of an observer would influence the work productivity of the same subjects in two study periods using pre-and post-observation methods. Two external fully registered pharmacists with experience in providing pharmacy services in the public sector were recruited as observers for this study. A session of study objectives and methods briefing was conducted for the observers before the study. The observers were trained by the principal investigator to observe and record the observations correctly.

\section{Work activities checklist}

A checklist of pre-defined work activities was customized and assembled to assist the observers in recording the activities of the subjects without the need for continual handwriting. Firstly, a brainstorming session was conducted among the research team members. All the possible work activities of the clinical pharmacists were first listed down based on the available literature and the local clinical pharmacy practice guidelines. These work activities were further summarized and categorized to form the final checklist which consisted of 16 main activity categories (Table 1).

The work tasks that required the pharmacy specialized skills or knowledge from the pharmacists to complete were grouped under the Clinical Activity category, such as participating in ward round, medication history assessments, and medication counselling. On the other hand, the work tasks that did not involve the use of specialized skills from the pharmacists were grouped under the Non-clinical Activity category, such as administrative works, housekeeping, and attending a meeting.

The consensus on the final draft of the checklist was reached among the research team and a panel of three senior clinical pharmacists in the practice and not involved in the study. The checklist was tested and improved in a pilot study before the actual data collection process started.

\section{The pilot study and the findings}

A two weeks pilot study was conducted before the commencement of the data collection. The pilot study aimed to prime the observers, to pilot and improve the work activities checklist, and to allow the subjects to adapt to the presence of the observer.

In the pilot study, the observers were placed together at the study site to observe and record the work activities of the subjects by using the work activities checklist. The results of the observations were compared among the observers in the discussions moderated by the principal investigator to improve the consistency of the observations collected. ${ }^{14}$ After three sessions of mock observations and agreement discussions, a final result of the agreement of $98.07 \%$ on 260 observation records was achieved by using the observer agreement test:

Reliability $(\%)=$ Number of agreements $\times 100 /$ (Number of agreements and disagreements)

Additionally, it was observed in the pilot study that the clinical pharmacists were often multitasking and performing more than one task at a time during the observation period. This significant finding was used to improve the study methods, such as the sample size estimation and the data collection process.

\section{Sample size}

The sample size in this study using the work sampling technique is referring to the number of observations taken. 
The sample size was calculated based on the proportion of time spent by the clinical pharmacists on providing clinical services, which was estimated to range from $56 \%$ to $96.2 \%$ from previous studies. ${ }^{18,24}$ The expected proportion of $78.6 \%$ was used as the parameter for the sample size calculator given the population characteristics of the study were similar to the present study. ${ }^{22}$

As a result, an observation number of 259 was required to achieve a $5 \%$ precision in estimating the proportion of time spent by the clinical pharmacists on providing clinical services by using the sample size calculator for estimating proportion. ${ }^{25}$ To improve the representability of the observed work activities carried out by the clinical pharmacists, every study subject was observed at least 259 times respectively.

\section{Observation}

The working hour of the clinical pharmacists starts from $8 \mathrm{am}$ to $5 \mathrm{pm}$ each day, with an hour lunch break from $1 \mathrm{pm}$ to $2 \mathrm{pm}$. This working interval was broken down into many segments of five minutes. A random number generator was used to assign 0 and 1 randomly to the segments to form an observation schedule. Observations were made according to the time segment assigned with 1. Each observation lasted five minutes with the work activities of the clinical pharmacists being monitored. No observation was made by the observer during the break times of the clinical pharmacists. A data collection period that lasted for six weeks was planned to allow all relevant activities of the clinical pharmacists to occur reasonably and hence to be captured in the study.

During the pilot study, it was observed that the clinical pharmacists were constantly multitasking on both clinical and non-clinical works during the five-minute observation interval, hence it was over-simplistic to conclude if that five-minute interval was spent entirely on clinical or nonclinical activity. Thus, the interval of five minutes was further divided and represented proportionately by the number of activities recorded during the observation. Every activity observed was counted as an 'event'. Every event was defined to be mutually exclusive and exhaustive. More than one different event could be recorded without repetition during each interval. For instance, two events could be recorded in the first five-minute interval, and four events being recorded in the next interval.

\section{Study period}

The data collection process of the present study started in January 2020 and lasted 30 consecutive working days (Monday to Friday). The observers took turns observing the subjects and only one observer was present at the study site at a time. The observers were instructed to observe the subject from a distance of two to three meters away so that they can identify the change of task easily without interrupting the subjects. A digital recurring chime application software was used by the observers to measure the five-minute interval.

\section{Pharmacy information system}

The pharmacy information system is an application software that is integrated with all pharmacy-related services. $^{26}$ This system is being used primarily in all Malaysian public hospitals to organize and maintain the medication use process within pharmacies. One key function of this application software is to serve as a monitoring system that captures and monitors pharmacy productivity. The productivity statistics are registered in the system in the normal course of the pharmacist's work such as medication label printing and infra-red barcode scanning of the medication during dispensing. However, the pharmacists still require to manually register certain work activities into the system due to the limitation of the pharmacy information system in defining the clinical work in unit, such as reporting the extent of the medication counselling and describing the detail of the clinical interventions. Nevertheless, the study subjects' productivity report captured by the pharmacy information system before and during the study was compared to estimate the extent of influence of the Hawthorne Effect in the present study.

\begin{tabular}{|c|c|c|c|c|c|c|c|c|c|c|}
\hline \multicolumn{11}{|c|}{ Timeline } \\
\hline \multicolumn{5}{|c|}{6 weeks ( 30 working days, Mon - Fri) } & \multirow[t]{2}{*}{2 weeks } & \multicolumn{5}{|c|}{6 weeks ( 30 working days, Mon - Fri) } \\
\hline 6 days & 6 days & 6 days & 6 days & 6 days & & 6 days & 6 days & 6 days & 6 days & 6 days \\
\hline \multirow[t]{5}{*}{$\begin{array}{c}\text { Subject } \\
\text { A }\end{array}$} & & & & & & $\begin{array}{c}\text { Subject } \\
\text { A }\end{array}$ & & & & \\
\hline & $\begin{array}{l}\text { Subject } \\
\text { B }\end{array}$ & & & & 1. Training & & $\begin{array}{c}\text { Subject } \\
\text { B }\end{array}$ & & & \\
\hline & & $\begin{array}{c}\text { Subject } \\
\text { C }\end{array}$ & & & $\begin{array}{l}\text { of the } \\
\text { observers }\end{array}$ & & & $\begin{array}{c}\text { Subject } \\
\text { C }\end{array}$ & & \\
\hline & & & $\begin{array}{c}\text { Subject } \\
\text { D }\end{array}$ & & 2. Pilot study & & & & $\begin{array}{c}\text { Subject } \\
\text { D }\end{array}$ & \\
\hline & & & & $\begin{array}{c}\text { Subject } \\
\text { E }\end{array}$ & & & & & & $\begin{array}{c}\text { Subject } \\
\text { E }\end{array}$ \\
\hline \multicolumn{5}{|c|}{$\begin{array}{l}\text { 1. The observers were not present. } \\
\text { 2. The ward BOR of the corresponding clinical } \\
\text { pharmacists was collected respectively from the patient } \\
\text { admission and discharge registry. } \\
\text { 3. The work productivity of the corresponding clinical } \\
\text { pharmacist was collected from the electronic pharmacy } \\
\text { information system, PhIS. }\end{array}$} & & \multicolumn{5}{|c|}{$\begin{array}{l}\text { 1. Actual study started and the observers were present at } \\
\text { the site of the study. } \\
2.6 \text { days of equal length of the ward BOR and the work } \\
\text { productivity of the corresponding clinical pharmacist } \\
\text { were collected similarly as before. } \\
\text { 3. The ward BOR and work productivity were compared } \\
\text { and analysed. }\end{array}$} \\
\hline
\end{tabular}

Figure 1. The data collection timeline of the bed occupancy rate and the subjects' work productivity for the baseline characteristics comparison 


\section{The Hawthorne effect}

During the conduct of the observational study, participants might feel disturbed and behave differently in the presence of an external observer. This phenomenon is known as the Hawthorne effect. ${ }^{17,27,28}$ The influence of the Hawthorne effect was reported as a source of bias to the study results in many works of literature given that the subjects being observed may deliberately improve or lower their performance to demonstrate an fluctuated result. ${ }^{29,30}$

A few study measures were being adopted in the present study to account for the Hawthorne effect as suggested by the literature. Firstly, a longitudinal study design was used whereby a large number of repeated observations were carried out on the same subjects. ${ }^{27,31}$ Secondly, the present study was planned with a two-week pilot study, followed by the actual data collection process conducted over 30 consecutive working days so that the Hawthorne effect may be diminished over time. It was anticipated by the study team that the influence of the Hawthorne effect on the initial observations collected was the highest, especially during the pilot study. Thus, all the observations recorded during the pilot study were discarded and the data analysis only involved the observations after the pilot study.

Lastly, a control comparator was used to measure the extent of the Hawthorne effect on the observation results (Figure 1). ${ }^{27}$ The work productivity of the subjects before the study (as the control group) was compared with the work productivity of the subjects post-study (as the intervention group). To measure the difference in the overall productivity caused by the Hawthorne effect, every work task completed by the pharmacists each day was converted into a measurable unit of 1 and later summed up for comparison. In this study, the term daily cumulative work unit is defined as the cumulative sum of every work unit of different work activity categories each day. For instance, a work unit could be a single prescription dispensed during discharge or one-time bedside counselling that was given to a patient and the sum of these work units of different categories give rise to the 2 daily cumulative work units in a day.

Two 30-day work productivity reports of the subjects before the study and during the study that were captured by the pharmacy information system were collected for a baseline characteristics comparison to test if the presence of the observers had any influence on the work productivity among the observed subjects. The bed occupancy rates during the two study periods were used as the indicator for the work burden on the clinical pharmacists, representing the number of patients present at the study site. ${ }^{32-34}$

\section{Statistical analysis}

The result on the number and type of activities observed was expressed in frequency, relative frequency, and 95\% confidence interval. The independent t-test was used to compare the mean bed occupancy rates in the ward of two independent study periods. As the work productivity of the subjects was inter-dependent in the two study periods (the observers were absent in the first study period and present in the second study period), the paired t-test was used to assess if the mean of the work productivity between the two study periods (as paired measurements) were significantly different. A p-value of less than 0.05 was considered significant.

\section{RESULTS}

Of the 11 clinical pharmacists invited, five voluntarily participated and became the subjects of the study for observation. All of the study subjects had completed the Malaysian one-year pharmacy residency training program, had a minimum of 18 months of working experience, and were familiar with daily working routines in the ward setting.

Every subject was present at work and did not have unplanned leave during the study. All of the observations were made during weekdays from Monday to Friday, with an average of 48.5 observations being made each day. A total of 1,455 observations were made over 121 hours and 15 minutes with 3,493 events recorded within the 30 days

Table 2. Summary of the events observed $(n=3493)$ and the average time percentage that the clinical pharmacists spent on various work activities

\begin{tabular}{|c|c|c|c|}
\hline Code & Category & $\begin{array}{l}\text { No. of event observed } \\
\text { (Percentage of activity) }\end{array}$ & 95\% Confidence interval \\
\hline \multicolumn{2}{|c|}{ Clinical service } & $2751(78.8)$ & 77.4: 80.1 \\
\hline 1. & Participating in ward round & $339(9.7)$ & $8.7: 10.7$ \\
\hline 2. & Medication history assessment and reconciliation & $156(4.5)$ & 3.8: 5.2 \\
\hline 3. & Case clerking \& medication review & $966(27.7)$ & 26.2: 29.1 \\
\hline 4. & Counselling & $134(3.9)$ & $3.2: 4.5$ \\
\hline 5. & Discharge planning & $180(5.2)$ & 4.4: 5.9 \\
\hline 6. & Distribution of information & $164(4.7)$ & 4.0: 5.4 \\
\hline 7. & Clinical risk management and drug surveillance & $24(0.6)$ & $0.4: 1.0$ \\
\hline 8. & Special authorization drug request processing & $9(0.3)$ & $0.1: 0.4$ \\
\hline 9. & Conducting intervention and keeping clinical records & $670(19.2)$ & 17.9: 20.5 \\
\hline 10. & Health communication & $109(3.1)$ & 2.5: 3.7 \\
\hline \multicolumn{2}{|c|}{ Non-clinical service } & $433(12.3)$ & 10.0: 14.9 \\
\hline 11. & Pharmacy administration and management & $134(3.8)$ & $3.2: 4.5$ \\
\hline 12. & Educational activities & $128(3.7)$ & 3.0: 4.3 \\
\hline 13. & Research-related activities & $7(0.2)$ & $0.1: 0.4$ \\
\hline 14. & Non-duty activities & $79(2.2)$ & 1.8: 2.8 \\
\hline 15. & Non-professional activities & $85(2.4)$ & 1.9: 2.9 \\
\hline \multicolumn{4}{|l|}{ Idle } \\
\hline 16. & Idle or work break & 309 (8.9) & 7.9: 9.8 \\
\hline
\end{tabular}


of study. Despite the minimum size of observation was achieved with 1295 observations, the results of the additional 160 observations were also included in the final analysis to improve the overall representability of the findings.

Overall, clinical pharmacists spent $78.8 \%(n=2,751)$ of their time providing clinical services (Table 2). The activities that occupied most of the pharmacists' working time were case clerking and medication review $(27.7 \%, \mathrm{n}=966)$, conducting intervention and records keeping $(19.2 \%, n=670)$, and participating in ward round $(9.7 \%, \mathrm{n}=339)$. In contrast, $12.3 \%(n=433)$ of the time was spent on non-clinical related activities, which comprised general pharmacy management work $(3.8 \%, n=134)$, educational activities $(3.7 \%, n=128)$, research-related activities $(0.2 \%, \mathrm{n}=7)$, non-duty activities (2.2\%, $n=79)$ and non-professional activities $(2.4 \%, n=85)$. The proportion of idle time was estimated to be $8.9 \%$ $(n=309)$.

There was no statistically significant difference in the baseline bed occupancy rate between the two 30-day periods $(p=0.384)$ (Table 3$)$. It was found that the clinical pharmacists had reported a significantly higher average number of patient medication history assessments done each day ( 3.10 vs $2.10, p=0.022$ ) when the observers were present. Otherwise, no significant difference was found in other work activities reported. The results demonstrated that the Hawthorne effect was present and had a positive influence on the overall work performance of the subjects as a higher average daily cumulative work unit of 9.8 $(S D=4.3)$ was reported among them when the observers were present compared to an average daily cumulative work unit of $6.5(S D=4.6)$ when the observers were absent $(p=0.005)$.

\section{DISCUSSION}

To the best of our knowledge, this was the first local study documenting how clinical pharmacists spent their working time on different types of work activities in the public hospital setting. The clinical pharmacists spent about $78.8 \%$ of the time providing clinical service. This result is similar to the other studies done using the work sampling technique under comparable conditions, which reported the clinical service time proportion to range from $72.36 \%$ to $78.6 \%{ }^{20,22}$ However, a large variation in the proportion of time spent on clinical service was also observed among previous studies done in the hospital setting which ranged from $56 \%$ to $96.2 \%$, depending on whether pharmacists were involved in administrative work. ${ }^{18,24}$

As demonstrated by previous studies, clinical pharmacists that did not have responsibilities in administrative works such as housekeeping, supervisory and managerial works, were allowed to allocate a bigger proportion of their time

\begin{tabular}{|c|c|c|c|c|c|c|}
\hline \multirow{3}{*}{ Code } & \multirow{3}{*}{ Variable } & \multirow{2}{*}{\multicolumn{2}{|c|}{$\begin{array}{l}\text { Work unit }{ }^{a} \text { in Mean (SD) } \\
\text { Presence of the observer }\end{array}$}} & \multirow{3}{*}{$\begin{array}{l}\text { Mean difference } \\
\quad(95 \% \mathrm{Cl})\end{array}$} & \multirow{3}{*}{$t$ stat. (df) } & \multirow{3}{*}{ p-value } \\
\hline & & & & & & \\
\hline & & No (30 days) & Yes (30 days) & & & \\
\hline \multicolumn{2}{|c|}{ Bed occupancy rate } & $79.61(8.09)$ & $81.37(7.49)$ & $1.76(-5.79,2.26)$ & $-0.87(58)^{c}$ & $0.384^{c}$ \\
\hline \multicolumn{2}{|c|}{ Daily cumulative work unit $^{\mathrm{e}}$} & $6.50(4.59)$ & $9.83(4.32)$ & $3.33(1.07,5.60)$ & $3.01(29)^{d}$ & $0.005^{d}$ \\
\hline \multicolumn{7}{|c|}{ CLINICAL ACTIVITY } \\
\hline 1. & Participating in ward round & \multicolumn{5}{|c|}{ Not available $^{b}$} \\
\hline 2. & $\begin{array}{l}\text { Medication history assessment \& reconciliation }{ }^{a} \\
\text { - No. of medication history assessment done }\end{array}$ & $2.10(1.77)$ & $3.10(1.63)$ & $1.00(0.16,1.84)$ & $2.43(29)^{d}$ & $0.022^{d}$ \\
\hline 3. & $\begin{array}{l}\text { Case clerking and medication review }{ }^{a} \\
- \text { No. of patient case clerked and reviewed }\end{array}$ & $1.40(1.65)$ & $2.03(1.61)$ & $0.63(-0.20,1.47)$ & $1.55(29)^{d}$ & $0.132^{d}$ \\
\hline 4. & $\begin{array}{l}\text { Counselling }{ }^{\text {a }} \\
- \text { No. of counselling session conducted }\end{array}$ & $1.23(2.01)$ & $2.10(1.90)$ & $0.87(-0.01,1.75)$ & $2.01(29)^{d}$ & $0.054^{d}$ \\
\hline 5. & Discharge planning & \multicolumn{5}{|c|}{ Not available ${ }^{b}$} \\
\hline 6. & $\begin{array}{l}\text { Distribution of information }{ }^{a} \\
- \text { No. of times of distributing drug info. }\end{array}$ & $0.57(1.17)$ & $0.60(1.00)$ & $0.03(-0.61,0.68)$ & $0.11(29)^{d}$ & $0.917^{d}$ \\
\hline 7. & Clinical risk management and drug surveillance & \multicolumn{5}{|c|}{ Not available $^{\mathrm{b}}$} \\
\hline 8. & Special authorization drug request processing & & & t available ${ }^{b}$ & & \\
\hline 9. & $\begin{array}{l}\text { Conducting intervention and keeping clinical } \\
\text { records }{ }^{a} \\
- \text { No. of intervention conducted and accepted } \\
\text { by the doctors }\end{array}$ & $1.20(1.92)$ & $2.00(1.82)$ & $0.80(-0.32,1.92)$ & $1.46(29)^{d}$ & $0.156^{\mathrm{d}}$ \\
\hline 10. & Health communication & \multicolumn{5}{|c|}{ Not available ${ }^{b}$} \\
\hline \multicolumn{7}{|c|}{ NON-CLINICAL ACTIVITY } \\
\hline 11. & Pharmacy administration and management & \multicolumn{5}{|c|}{ Not available $^{b}$} \\
\hline 12. & Educational activities & \multicolumn{5}{|c|}{ Not available ${ }^{b}$} \\
\hline 13. & Research-related activities & \multicolumn{5}{|c|}{ Not available $^{b}$} \\
\hline 14. & Non-duty activities & \multicolumn{5}{|c|}{ Not available $^{b}$} \\
\hline 15. & Non-professional activities & \multicolumn{5}{|c|}{ Not available ${ }^{b}$} \\
\hline \multicolumn{7}{|l|}{ IDLE } \\
\hline 16. & Idle or work break & \multicolumn{5}{|c|}{ Not available $^{\mathrm{b}}$} \\
\hline \multicolumn{7}{|c|}{$\begin{array}{l}{ }^{a} \text { Every work task completed and reported by the clinical pharmacist in the electronic pharmacy information system (PhIS) each day was } \\
\text { converted into a measurable unit of } 1 \text { and summed up for the general work productivity comparison in the present study } \\
\text { bo } \\
\text { b Statistics were not available due to not being captured by the PhIS } \\
\text { e Daily cumulative daily work unit is defined as the cumulative sum of every work unit in different work activity categories in a day. Hereby it is } \\
\text { referring to the cumulative sum of all work units in work activity No. 2, No. 3, No. 4, No. 6, and No. } 9\end{array}$} \\
\hline
\end{tabular}


to clinical-related activities. ${ }^{18,35,36}$ For example, a study done on observing hospital pharmacists' working patterns in Australia has reported $96.2 \%$ of the time spent by ward pharmacists on clinical services. In this study, the pharmacists were only involved in four main clinical activity categories such as medication review, drug monitoring, counselling, and discharge planning, which resulted in a high reported time proportion spent on clinical activities.

In contrast, work that did not require cognitive pharmaceutical skills from ward pharmacists took up a significant amount of time as demonstrated by the work sampling studies conducted in several other countries; in the UK which reported a clinical time proportion of $58 \%$;in the USA which reported the clinical time proportion ranging from $60 \%$ to $83 \%$; and in Japan which reported a clinical time proportion of $78.6 \% .{ }^{19-22}$ It is worth noting that the pharmacists in these studies were all involved significantly in non-clinical activities such as supervisory, managerial, and administrative work, which consequently resulted in a lower reported time spent on clinical activities. ${ }^{19-22,24,37,38}$ The large variability among these findings across different studies was possibly due to the differences in job scope definitions and the service focus in particular settings. Hence, direct comparison of the findings is difficult and should only be undertaken on studies with similar work settings.

This study has found that there was no statistics or work report available in the pharmacy information system to reflect the efforts of clinical pharmacists that were put in the five major clinical activity categories (Table 3). Of the $78.8 \%$ of the time spent by the clinical pharmacists on clinical works, only $59.9 \%$ of the time spent on work was reflected in the pharmacy information system (Table 2 ). It was estimated that the unreflected work activities have taken up $18.9 \%$ of the clinical pharmacists' working time. Subsequently, policymakers are only able to observe the efforts of the pharmacists $59.9 \%$ of the time, resulting in excessive workload on top of their daily duties.

Despite the pharmacists in this study were observed to carry out the activities as part of their daily duty, it was found out later that these activities were not required to be recorded in any way. Given those activities are not the key components that constitute the key performance indicator on the service provided, therefore they are not counted as part of the key performance indicators. This finding is in agreement with other studies, that the effort and the contribution behind a work unit can be easily underrepresented because of the difficulty in assessing what is constituted as one unit of clinical work. ${ }^{11,12,14,39}$ On the other hand, about $12.3 \%$ of the time spent by the pharmacists on non-clinical activities was entirely unreflected by the pharmacy information system.

The Hawthorne effect was present in this study despite few study measures were taken to control its influence on the study result. The observer's action of maintaining attention on the subjects during observation had exerted a positive effect on the productivity of the study subjects. It should be emphasized that the difference in the productivity result between the two periods may be confounded by the time and work burden factors of the subjects, given that they were required to register some of the completed work units into the pharmacy information system at their own time which was very much depending on their work on hand.

However, the similar bed occupancy rate at the site of the study suggested that the workloads of the pharmacists should be similar between the study periods by assuming that the number of patients was the main source of workloads. Nevertheless, overcoming Hawthorne effect remains challenging in observational studies and it is possible the pharmacists may behave differently during study observation compared to normal working hours.

\section{Strengths and limitations}

This study compared the general work productivity of the subjects by comparing the cumulative work unit from different work activities. This method was not reported in other studies before. In view of the number of work units report in each category was too small to detect a statistically significant difference, it was difficult to draw a conclusion whether the difference existed in the overall work productivity given that not all of the work categories showed a difference simultaneously. It is worth noting that the time and effort spent in completing every work unit may be varied and adding various work units together may lead to misestimating the subjects' productivity. Nevertheless, the direct comparison of the cumulative work unit provides a simple means of detecting the influence of the Hawthorne effect on work performance.

It should be acknowledged that this study did not look at the effect of other factors such as the overall patient complexity, the rate of nursing staff, and houseman turnover in the ward which may contribute to the difference in the study results. ${ }^{40-42}$ By using the bed occupancy rate as the only indicator could lead to misestimation of workload and hence resulting in the study bias for the two study phases. Moreover, the length and the quality of care provided by the pharmacists were not measured in this study. This is because it is difficult to assess what constitutes a clinical work for measurement and hence difficult to be measured. Lastly, the present study can only capture the work activities of the clinical pharmacists that performed within the observation window. The work activities that were performed outside of the observation schedule, such as after hours, during the weekend were not reflected in this study.

\section{CONCLUSIONS}

The present study has identified the range of work activities of clinical pharmacists under the impact of employment system changes in the public sector. These pharmacists are required to share the workload of nonclinical tasks instead of dedicating their full attention to providing clinical care to patients. Given that no alternative comprehensive work reporting system is available, the work effort of clinical pharmacists is commonly underrepresented, which resulted in a vicious cycle of excessive work being given to them on top of their daily duties. Policymakers should redesign their workflow and redefine the range of measurable work activities that are within their daily working duties. The present study recommends the relevant stakeholders consider reducing 
the workload of clinical pharmacists in non-clinical areas so that these clinical pharmacists can dedicate more time in providing patient care as an important step towards improving the quality of clinical service delivery.

\section{ACKNOWLEDGMENT}

We would like to thank the Director General of Health Malaysia for his permission to publish this article. We would like to extend our appreciation to Dr. Ooi Cheng Lee who served as the scientific advisor and critically reviewed the first draft of the manuscript. We would like to thank Ms. Nicole Mak Weng Teng who helped with the language editing.

\section{CONFLICT OF INTEREST}

The author(s) declare(s) that they have no conflicts of interest to disclose.

\section{FUNDING}

This research received no specific grant from any funding agency in the public, commercial, or not-for-profit sectors.

\author{
AUTHOR ROLES (CRediT) \\ Conceptualization: KKK, SCO, GSO, MAH. \\ Data curation: KKK, SCO. \\ Formal analysis: KKK. \\ Investigation: KKK. \\ Methodology: KKK, SCO. \\ Project administration: KKK. \\ Supervision: KKK, SCO, GSO, MAH. \\ Validation: KKK, SCO. \\ Visualization: KKK. \\ Writing - original draft: KKK, SCO. \\ Writing - review \& editing: KKK, SCO, GSO, MAH.
}

\section{References}

1. Hassali MAA, Shafie AA, See OG, Wong ZY. Chapter 2 - Pharmacy Practice in Malaysia. In: Fathelrahman Al, Ibrahim MIM, Wertheimer Al, editors. Pharmacy Practice in Developing Countries. Boston: Academic Press; 2016.

2. Pharmaceutical Service Programme MoHM. Our history 2013. https://www.pharmacy.gov.my/v2/en/content/ourhistory.html (accessed Feb 1, 2021).

3. Liew SJX. Malaysia's MOH Contract Pharmacists: Stuck in Limbo? https://mpsypc.com.my/publications/malaysias-mohcontract-pharmacists-stuck-in-limbo/ (accessed Apr 19, 2021).

4. Atun R, Berman P, Hsiao W, Myers E, Yap WA. Malaysia Health System Research (MHSR) Volume 1, contextual analysis of the Malaysian health system March 2016. Malaysia: MHSR; 2016.

5. Fathelrahman A, Ibrahim M, Wertheimer A. Pharmacy practice in developing countries: achievements and challenges. Boston: Academic Press; 2016.

6. Abida Haq SMH, Ainul Salhani AR, Rabi'ah M, Phuah HL. Guidelines for Inpatient Pharmacy Practice. 1st ed. Ministry of Health Malaysia; 2010.

7. Bond CA, Raehl CL. Clinical pharmacy services, pharmacy staffing, and hospital mortality rates. Pharmacotherapy. 2007;27(4):481-493. https://doi.org/10.1592/phco.27.4.481

8. Chisholm-Burns MA, Kim Lee J, Spivey CA, et al. US pharmacists' effect as team members on patient care: systematic review and meta-analyses. Med Care. 2010;48(10):923-933. https://doi.org/10.1097/mlr.0b013e3181e57962

9. Gillespie U, Alassaad A, Henrohn D, et al. A comprehensive pharmacist intervention to reduce morbidity in patients 80 years or older: a randomized controlled trial. Arch Intern Med. 2009;169(9):894-900. https://doi.org/10.1001/archinternmed.2009.71

10. Kaboli PJ, Hoth AB, McClimon BJ, Schnipper JL. Clinical pharmacists and inpatient medical care: a systematic review. Arch Intern Med. 2006;166(9):955-964. https://doi.org/10.1001/archinte.166.9.955

11. Boardman H, Fitzpatrick R. Self reported clinical pharmacist interventions under-estimate their input to patient care. Pharm World Sci. 2001;23(2):55-59. https://doi.org/10.1023/a:1011270507539

12. Parrish RH 2nd. Lecture 3-Measuring Pharmacy's Work in the 21st Century. Pharmacy (Basel). 2018;6(3):63. https://doi.org/10.3390/pharmacy6030063

13. Millar T, Sandilya R, Tordoff J, Ferguson R. Documenting pharmacist's clinical interventions in New Zealand hospitals. Pharm World Sci. 2008;30(1):99-106. https://doi.org/10.1007/s11096-007-9150-y

14. Rutter PM, Brown D, Jones IF. Pharmacy research: the place of work measurement. Int J Pharm Pract. 1998;6:46-58. https://doi.org/10.1111/i.2042-7174.1998.tb00915.x

15. Guarisco S, Oddone E, Simel D. Time analysis of a general medicine service: results from a random work sampling study. J Gen Intern Med. 1994;9(5):272-277. https://doi.org/10.1007/bf02599655

16. Rascati KL, Kimberlin CL, McCormick WC. Work measurement in pharmacy research. Am J Hosp Pharm. 1986;43(10):2445-2452.

17. Sittig DF. Work-sampling: a statistical approach to evaluation of the effect of computers on work patterns in the healthcare industry. Proc Annu Symp Comput Appl Med Care. 1992;537-541.

18. Stuchbery $P$, Kong DC, Desantis GN, Lo SK. Identification by observation of clinical pharmacists' activities in a hospital inpatient setting. Pharm Pract (Granada). 2007;5(1):10-16. https://doi.org/10.4321/s1886-36552007000100002

19. Jenkins D, Cairns C, Barber N. How do ward pharmacists spend their time?: an activity sampling study. Int J Pharm Pract. 1992;1(3):148-151. https://doi.org/10.1111/i.2042-7174.1992.tb00557.x

20. Barsness FR, Trinca CE. Activity analysis and cost study of clinical pharmacists practicing in a university medical center: comparison with previously established criteria. Drug Intell Clin Pharm. 1978;12(5):284-294. https://doi.org/10.1177/106002807801200504 
21. Guerrero RM, Nickman NA, Bair JN. Work activities of pharmacy teams with drug distribution and clinical responsibilities. Am J Health Syst Pharm. 1995;52(6):614-620. https://doi.org/10.1093/ajhp/52.6.614

22. Hamai T, Kimura M, Suzuki T, Misaki Y, Shiga Y, Nishigaki M. Work Measurement in Clinical Pharmacist's Activities. Iryo Yakugaku. 2001;27(3):193-204. https://doi.org/10.5649/jiphcs.27.193

23. Panthong S, Daosodsai P. Work Analysis Model Of Hospital Pharmacy Services: Case Study In Outpatient Dispensing Services At Banphai Hospital, Thailand. Malaysian J Pharm Sci. 2005;3(2):66.

24. de Clifford JM, Blewitt $P$, Lam SS, Leung BK. How do clinical pharmacists spend their working day? A time and motion study. J Pharm Pract Res. 2012;42(2):134-139. https://doi.org/10.1002/i.2055-2335.2012.tb00151.x

25. Naing L, Winn T, Rusli BN. Practical Issues in Calculating the Sample Size for Prevalence Studies. Archives of Orofacial Sciences. 2006;1:9-14

26. Pharmaceutical Services Division and Information Management Division MoHM. Overview and Background Project PhIS \& CPS. https://phisportal.moh.gov.my/project-profile/pharmacy-information-system-phis-dan-clinic-pharmacy-system-cps (accessed Jun 11, 2021).

27. Holden JD. Hawthorne effects and research into professional practice. J Eval Clin Pract. 2001;7(1):65-70. https://doi.org/10.1046/i.1365-2753.2001.00280.x

28. Oswald D, Sherratt F, Smith S. Handling the Hawthorne effect: The challenges surrounding a participant observer Review of Social Studies. 2014;1(1):53-73.

29. McCambridge J, Witton J, Elbourne DR. Systematic review of the Hawthorne effect: new concepts are needed to study research participation effects. J Clin Epidemiol. 2014;67(3):267-277. https://doi.org/10.1016/i.jclinepi.2013.08.015

30. Lopetegui M, Yen PY, Lai A, Jeffries J, Embi P, Payne P. Time motion studies in healthcare: what are we talking about?. J Biomed Inform. 2014;49:292-299. https://doi.org/10.1016/i.jbi.2014.02.017

31. Lehmann C, Nowak A. The Hawthorne effect: can it be measured and utilized?. Br J Anaesth. 2013;110(4):658-659. https://doi.org/10.1093/bja/aet035

32. Friebel R, Fisher R, Deeny SR, Gardner T, Molloy A, Steventon A. The implications of high bed occupancy rates on readmission rates in England: A longitudinal study. Health Policy. 2019;123(8):765-772. https://doi.org/10.1016/i.healthpol.2019.06.006

33. Cucolo DF, Perroca MG. The qualitative dimension of Nursing workload: a measurement proposal. Rev Lat Am Enfermagem. 2019;27:e3238. https://doi.org/10.1590/1518-8345.3274.3238

34. Briatte I, Allix-Béguec C, Garnier G, Michel M. Revision of hospital work organization using nurse and healthcare assistant workload indicators as decision aid tools. BMC Health Serv Res. 2019;19(1):554. https://doi.org/10.1186/s12913-0194376-7

35. Fisher AM, Ding MQ, Hochheiser H, Douglas GP. Measuring time utilization of pharmacists in the Birmingham Free Clinic dispensary. BMC Health Serv Res. 2016;16(1):529. https://doi.org/10.1186/s12913-016-1787-6

36. Negaard BJ, Lyons KP, Nichol CL, Polgreen LA. What does a pharmacist do? A time and motion study. Res Social Adm Pharm. 2020;16(9):1314-1317. https://doi.org/10.1016/j.sapharm.2019.03.007

37. English S, Hort A, Sullivan N, Shoaib M, Chalmers L. Is ward round participation by clinical pharmacists a valuable use of time and money? A time and motion study. Res Social Adm Pharm. 2020;16(8):1026-1032. https://doi.org/10.1016/i.sapharm.2019.10.014

38. Wirth F, Azzopardi LM, Gauci M, Adami MZ, Serracino-Inglott A. Time and motion study for pharmacists' activities in a geriatric hospital. INt J Pharm Pract. 2009;17(6):373-376. https://doi.org/10.1211/ijpp.17.06.0010

39. ASHP. Workload Monitoring and Reporting. Pharmacy Management. Bethesda: American Society of Health-System Pharmacists; 2013

40. Olthof M, Stevens M, Dijkstra B, Bulstra SK, Van Den Akker-Scheek I. Actual and perceived nursing workload and the complexity of patients with total hip arthroplasty. Appl Nurs Res. 2018;39:195-199. https://doi.org/10.1016/.apnr.2017.11.023

41. Tommasi V, Campolongo A, Caridi I, et al. Variables determining clinical complexity in hospitalized Internal Medicine patients: A workload analysis. Italian J Med. 2017;11:202. https://doi.org/10.4081/itjm.2017.725

42. Unruh LY, Fottler MD. Patient turnover and nursing staff adequacy. Health Serv Res. 2006;41(2):599-612. https://doi.org/10.1111/i.1475-6773.2005.00496.x 